\title{
VIRTUAL POWER PLANT AS A REMEDY TO THE POWER CRISIS OF BANGLADESH: A CASE STUDY-CUET
}

\author{
C. K. Das ${ }^{(1)}$, N. K. Das ${ }^{(1)}$, M. M. Islam ${ }^{(1)}$ and S.M. Sazzad Hossain ${ }^{(1)}$ \\ 1. Department. of Electrical \& Electronic Engineering, Chittagong University of Engineering \& Technology \\ E-mail: choton46@yahoo.com,nipu16@gmail.com,muin_028@yahoo.com,shuvo_eee05@yahoo.com
}

6.

\begin{abstract}
A virtual power plant is a cluster of distributed generation installations (such as microchip, wind-turbines, small hydro, back-up genets etc.) which are collectively run by a central control entity. The concerted operational mode shall result in an extra benefit as to deliver peak load electricity or load following power at short notice. Bangladesh is facing acute power crisis like other developing countries. As we have limited resources we have to think economically.VPP is playing good role in European \& American market. So we have taken VPP as a solution for power crisis. In this thesis, we have taken CUET as a reference model. To solve the power crisis in CUET \& to supply power to the main grid a small virtual power plant is designed . Whole CUET is divided into three regions for designing purpose. By using MATLAB simulink environment machine characteristic curves are derived \& cost is calculated.
\end{abstract}

KEY WORDS: VPP, MATLAB, DG, CUET, MCCB, DER, LDC.

\subsection{INTRODUCTION}

The small scale power generating technology, such as micro hydro, photovoltaic, wind turbine and micro turbine are gradually replacing conventional/traditional technologies in various applications. They are identified as distributed generation (DG), the DG technology is often lumped with distributed storage and their combination is referred to as distribution energy resources (DER) modular electric generation or at storage installed at customer site. The distributed generations have many benefits, such as low transmission losses, high fuel efficiency, short construction lead time, modular installation and low emission, which all contribute to their growing popularity and DG offers great value. It provides a flexible way to choose a wide range of combination of cost and reliability that means it can play a vital role in the impending distributed generation market ${ }^{[1]}$.

Furthermore, penetration/deployment of DER at main grids emerged new concepts such as Micro grids and Virtual Power Plant (VPP). These concepts are radically different methods for designing operating power system and also hold the potential for providing the high reliability, quality, security, and availability of electrical service required by emerging digital society.

\subsection{CONCEPT OF VPP}

\section{VPP DEFINITION:}

Virtual power plant are formed by a mix of decentralized generation, storage \& load units on particular supply areas that show similar reliable, plan able \& controllable behavior as larger central generators or loads. This is in spite of different profiles of the units that form these balanced supply areas the adherence to schedules (import \& export energy) that have been communicated in advance to higher level management systems. There are different possibilities for vertical \& horizontal integration of these VPP. Thus one VPP can be included into an overlaying VPP. It is possible to connect several different VPP to existing distribution management systems ${ }^{[2]}$.

\section{TYPES OF VPP:}

\section{Centralized VPP \& DECENTRALIZED VPP}

In Centralized System Topology, DG units are controlled by control coordination centre which is located right in the figure. The load signals are transmitted to CCC where it is processed by means of logic algorithm [1]. In decentralized system topology, each DG unit is locally controlled by local controller (LC) ${ }^{[3]}$. To perform an integrated system, the local controllers are connected/linked to each other forming ring network architecture through communication to allow signals exchange ${ }^{[1]}$. The communication system will be SCADA ${ }^{[4]}$. 


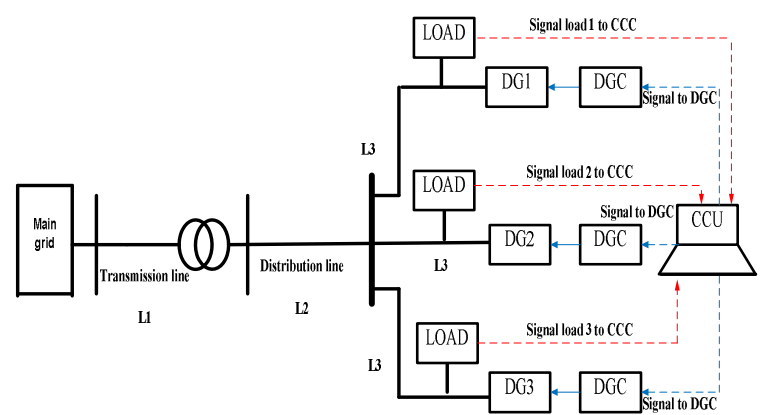

Figure 1: Centralized VPP

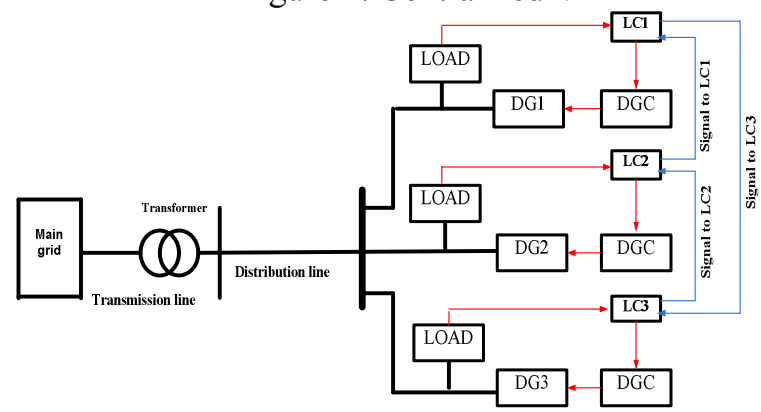

Figure 2: Decentralized VPP

\subsection{SySTEM DESIGN}

\subsection{A CASE STUdY FOR CUET:}

As CUET is situated in rural area, here load shedding occurs frequently. So power crisis solution is necessary. It is easy to calculate total connected load \& also to measure the peak \& off-peak load. As CUET is small region we can easily install a VPP in low cost.

\subsection{REASON OF CHOOSING CENTRALIZED VPP FOR CUET:}

Centralized Controlled VPP requires the control over each of the DER being part of the VPP, including access to their relevant real-time performance data. Obviously the centralized controlled model requires that the owners of the production units are willing to let go of the control of their units. Therefore the model would perhaps apply better to a scenario where the VPP owned the distributed production units instead of private individuals or companies. Centralized Controlled VPP seems to be best fitted for integrating existing DER into a VPP and best at handle relatively small amounts of DER since the amount of data in the VPP increases significantly with every DER added to the VPP. In a small region like CUET decentralized VPP will less economical benefits compare to the centralized VPP because it will require more control centre \& communication infrastructure. Besides this, it will require more trained person to operate. For this reason centralized VPP will be best fitted.

\subsection{Present Power Distribution In CUET CAMPus:}

A main transformer of $500 \mathrm{KVA}$ step downs the 11 $\mathrm{kV}$ transmission line into $0.415 \mathrm{kV}$ in substation located near the CUET ladies hall. Power is provided from the substation to CUET Campus through $0.415 \mathrm{kV}$, transmission lines that terminate from CUET main distribution switchgear. The main bus of the switchgear is arranged in a way to allow no interruption of continuity of power to the campus. $0.415-\mathrm{kV}$ distribution throughout the entire CUET campus is accomplished by eleven distribution circuit breakers present in the CUET main switchgear. A MCCB circuit breaker of 800 amps controls the other ten circuit breakers and these breakers controls the power supply to different buildings of the campus.

\subsection{CENTRALIZED VPP FOR CUET:}

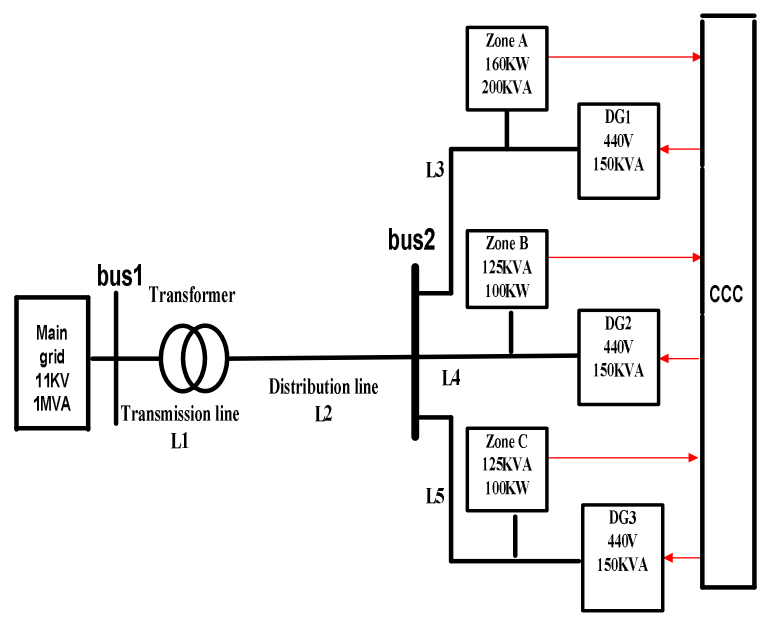

Figure 3: Block diagram for centralized VPP for CUET.

We divided the whole CUET in three zones

Zone A: EME,CE+CSE building, 12 storied building, PEB, Academic section, Workshop, Library, Gallery, Medical centre, Post office, Bank, Transport section, Mosque, CUET school \& college. Zone B: student halls \& extension

Zone C: Residential area, Anser camp, guard shed, street light \& water pump

\begin{tabular}{|c|c|c|c|c|}
\hline Zone & $\begin{array}{c}\text { Peak } \\
\text { Hour }\end{array}$ & $\begin{array}{c}\text { Peak } \\
\text { Load }\end{array}$ & $\begin{array}{c}\text { Off Peak } \\
\text { hour }\end{array}$ & $\begin{array}{c}\text { Off } \\
\text { peak } \\
\text { Load }\end{array}$ \\
\hline A & $\begin{array}{c}8.00 \mathrm{AM}- \\
5.00 \mathrm{PM}\end{array}$ & $\begin{array}{c}160 \mathrm{KW} \\
\text { (approx) }\end{array}$ & $\begin{array}{c}5.00 \mathrm{PM}- \\
8.00 \mathrm{AM}\end{array}$ & $\begin{array}{c}30 \mathrm{KW} \\
\text { (approx })\end{array}$ \\
\hline B & $\begin{array}{c}7.00 \mathrm{PM}- \\
12.00 \mathrm{AM}\end{array}$ & $\begin{array}{c}100 \mathrm{KW} \\
\text { (approx) }\end{array}$ & $\begin{array}{c}12.00 \mathrm{AM} \\
-7.00 \mathrm{PM}\end{array}$ & $\begin{array}{c}30 \mathrm{KW} \\
\text { (approx) }\end{array}$ \\
\hline $\mathrm{C}$ & $\begin{array}{c}7.00 \mathrm{PM}- \\
12.00 \mathrm{AM}\end{array}$ & $\begin{array}{c}100 \mathrm{KW} \\
\text { (approx) }\end{array}$ & $\begin{array}{c}12.00 \mathrm{AM} \\
-7.00 \mathrm{PM}\end{array}$ & $\begin{array}{c}30 \mathrm{KW} \\
\text { (approx })\end{array}$ \\
\hline
\end{tabular}


So we need three synchronous generator of rating $200 \mathrm{kva}$ (zone A) \& 125kva (for zone B\&C)

We assume the transformer rating $450 \mathrm{kva} \&$ $11 \mathrm{kv} / 440 \mathrm{v}$

\section{CAlCulation OF R-L-C:}

All branches in simulation are represented by three phase parallel RLC branch.

The length of overhead lines (L1) is $500 \mathrm{~m}$, thus the $\mathrm{R}-\mathrm{L}-\mathrm{C}$ value can be obtained:

$\mathrm{R}_{1}=0.356 \mathrm{ohm} / \mathrm{km} \times 0.5 \mathrm{~km}=0.178 \mathrm{ohm}$

$\mathrm{X}_{1}=2 . \pi . \mathrm{f} . \mathrm{L}=0.3226 \mathrm{ohm} / \mathrm{Km}=0.3226 \times 0.5$ $\mathrm{ohm}=0.1613 \mathrm{ohm}$

$\mathrm{L}_{1}=\frac{X}{2, \pi . f}=\frac{0.3226}{2 * 3.1416 * 50}=1.027 \mathrm{e}^{-03} \mathrm{H} / \mathrm{Km}=1.027 \mathrm{e}^{-03}$

$\mathrm{H} / \mathrm{Km} \times 0.5 \mathrm{Km}=5.13 \mathrm{e}^{-04} \mathrm{H}$

$\mathrm{C}_{1}=235 \mathrm{Nf} / \mathrm{Km} \times 0.5 \mathrm{Km}=117.5 \mathrm{Nf}$

The R-L-C value of overhead line (L2 =100 m) can be calculated:

$\mathrm{R}_{2}=0.2426 \mathrm{ohm} / \mathrm{Km} \times 0.1 \mathrm{Km}=0.02426 \mathrm{ohm}$

$\mathrm{X}_{2}=0.3614 \mathrm{ohm} / \mathrm{Km} \times 0.1 \mathrm{Km}=0.03614 \mathrm{ohm}$

$\mathrm{L}_{2}=\frac{0.03614}{2 * 3.1416 * 50}=1.150 \mathrm{e}^{-04} \mathrm{H}$

$\mathrm{C}_{2}=10.12 \mathrm{Nf} / \mathrm{Km} \times 0.1 \mathrm{Km}=1.012 \mathrm{Nf}$

The R-L-C value of overhead line $(\mathrm{L} 3=100 \mathrm{~m})$ can be calculated:

$\mathrm{R}_{3}=0.437 \mathrm{ohm} / \mathrm{Km} \times 0.1=0.0437 \mathrm{ohm}$

$\mathrm{X}_{3}=0.302 \mathrm{ohm} / \mathrm{Km} \times 0.1=0.0302 \mathrm{ohm}$

$\mathrm{L}_{3}=\frac{0.0302}{2 * 3.1416 * 50}=9.613 \mathrm{e}^{-05} \mathrm{H}$

$\mathrm{C}_{3}=10.2 \mathrm{Nf} / \mathrm{Km} \times 0.1 \mathrm{Km}=1.02 \mathrm{Nf}$

The R-L-C value of overhead line $(\mathrm{L} 4=1 \mathrm{Km})$ can be calculated:

$\mathrm{R}_{4}=0.437 \mathrm{ohm} / \mathrm{Km} \times 1=0.437 \mathrm{ohm}$

$\mathrm{X}_{4}=0.302 \mathrm{ohm} / \mathrm{Km} \times 1=0.302 \mathrm{ohm}$

$\mathrm{L}_{4}=\frac{0.302}{2 * 3.1416 * 50}=9.613 \mathrm{e}^{-04} \mathrm{H}$

$\mathrm{C}_{4}=10.2 \mathrm{Nf} / \mathrm{Km} \times 1 \mathrm{Km}=10.2 \mathrm{Nf}$

The R-L-C value of overhead line $(\mathrm{L} 5=1 \mathrm{Km})$ can be calculated:

$\mathrm{R}_{5}=0.437 \mathrm{ohm} / \mathrm{Km} \times 1=0.437 \mathrm{ohm}$

$\mathrm{X}_{5}=0.302 \mathrm{ohm} / \mathrm{Km} \times 1=0.302 \mathrm{ohm}$

$\mathrm{L}_{5}=\frac{0.302}{2 * 3.1416 * 50}=9.613 \mathrm{e}^{-04} \mathrm{H}$

$\mathrm{C}_{5}=10.2 \mathrm{Nf} / \mathrm{Km} \times 1 \mathrm{Km}=10.2 \mathrm{Nf}$

Resistance and Inductance of Transformer:

For each winding the per unit resistance and inductance are defined [5] as:

$\mathrm{R}_{\text {pu }}=\mathrm{R}(\Omega) / \mathrm{R}_{\text {base }}$

$\mathrm{L}_{\mathrm{pu}}=\mathrm{L}(\mathrm{H}) / \mathrm{L}_{\text {base }}$

The base resistance and base inductance used for each winding are

$\mathrm{R}_{\text {base }}=\left(\mathrm{V}_{\mathrm{n}}\right)^{2} / \mathrm{P}_{\mathrm{n}}$

$\mathrm{L}_{\text {base }}=\left(\mathrm{R}_{\text {base }}\right) /\left(2 . \pi . \mathrm{f}_{\mathrm{n}}\right)$
For the magnetization resistance $\mathrm{R}_{\mathrm{m}}$ and inductance $\mathrm{L}_{\mathrm{m}}$, the p.u values are based on the transformer rated power and on nominal voltage of the winding one.

$\mathrm{R}_{\text {base }}=\left((11 / \sqrt{3})^{2} / 450\right) \times 1000=89.63 \Omega$

$\mathrm{L}_{\text {base }}=\frac{99.63}{2 \times 3.1416 \times 50}=0.285 \mathrm{H}$

Data from grid reference for $\mathrm{R}=.178 \mathrm{ohm}$ and $\mathrm{X}=$ $0.1613 \mathrm{ohm}$. Therefore to obtained L:

$\mathrm{L}_{1}=\frac{X 1}{2 \times \pi \times f}=\frac{0.1613}{2 \times 3.1416 \times 50}=0.0005 \mathrm{H}$

Supposed that the windings transformer $\left(\mathrm{R}_{1}\right)=$ $0.178 \Omega \&\left(\mathrm{~L}_{1}\right)=0.0005 \mathrm{H}$, the corresponding values to be entered in the simulation block are:

$\mathrm{R}_{1}=\frac{0.178}{89.63}=0.002 \mathrm{p} . \mathrm{u}$

$\mathrm{L}_{1}=\frac{0.0005}{0.285}=0.002 \mathrm{p} . \mathrm{u}$

To specify a magnetizing current of $0.3 \%$ (resistive and inductive) based on nominal current. Thus the per unit values of $1 / 0.003=314$ p.u for resistance and the inductance of the magnetizing branch.

\subsection{Simulation}

\section{MATLAB SimULINK DESIGN:}

We have used MATLAB 7.6 for simulation. The components are available in power system library in Matlab Simulink and each model parameters are fulfilled with the proper data from grid reference.

\subsection{THE THREE-PHASE AC SOURCE BLOCK:}

The Three-Phase Source block implements a balanced three-phase voltage source with internal R$\mathrm{L}$ impedance. The three voltage sources are connected in $\mathrm{Y}$ with a neutral connection that can be internally grounded or made accessible. The source internal resistance and inductance are either by directly entering $\mathrm{R}$ and $\mathrm{L}$ values or by indirectly specifying the source inductive short-circuits level and $\mathrm{X} / \mathrm{R}$ ratio. The base voltage is $11 \mathrm{kV}_{(\mathrm{rms})}$ and the frequency system is $50 \mathrm{~Hz}$.

\subsection{Transmission AND Distribution Line:}

This section describes each of the branches that transmit electrical power. The branches are usually lines or cables.

There are aerial lines at the $11 \mathrm{kV}$ and $0.44 \mathrm{kV}$ voltage level which is responsible for distributing power at lower voltage levels. Each branch is described in detail with explanation of the values used for the electrical parameters. The three-phase parallel RLC branch block implements three balanced branches consisting each of a resistor (in ohms- $\Omega$ ), an inductor (in henries-H), a capacitor (in 
farads-F), or a parallel combination of these. Each branch data is described in table 1 .

\begin{tabular}{|c|c|c|c|c|}
\hline No & Type & $\begin{array}{c}\mathrm{X} \\
(\mathrm{ohm} / \\
\mathrm{km})\end{array}$ & $\begin{array}{c}\mathrm{R} \\
(\mathrm{ohm} / \\
\mathrm{km})\end{array}$ & $\begin{array}{c}\mathrm{C} \\
(\mathrm{nF} / \\
\mathrm{km})\end{array}$ \\
\hline 1 & $\begin{array}{c}\text { Overhead line } \\
(\mathrm{L} 1)\end{array}$ & .3226 & .356 & 235.00 \\
\hline 2 & $\begin{array}{c}\text { Overhead line } \\
(\text { L2 })\end{array}$ & .3614 & .2426 & 10.12 \\
\hline 3 & $\begin{array}{c}\text { Distribution } \\
\text { line (L3, L4 \& } \\
\text { L5) }\end{array}$ & .302 & .437 & 10.2 \\
\hline
\end{tabular}

Table 1: Data lines parameters

The typical data line parameters as shown above particularly for low voltage line is simulation are represented by three phase parallel RLC branch. The lengths of overhead lines L1 is $0.5 \mathrm{~km}$. At low voltage level, the length of distribution line (L2) from step down transformer to distribution bus is 0.1 $\mathrm{km}$ and length distance from distribution bus to each loads/DG units are $0.1 \mathrm{~km}$ for L3, $1 \mathrm{~km}$ for L4 \& L5.

\subsection{STEP DOWN TRANSFORMER:}

As shown in figure, the system has only one transformer. The three-phase transformer (two windings) block implements a three-phase transformer using three single-phase transformers. The nominal power rating of the transformer is in volt-amperes (VA), and nominal frequency in hertz $(\mathrm{Hz})$. The primary side bus bar is $11 \mathrm{kV}$, and the secondary bus bar is $440 \mathrm{~V}$. The secondary bus bar is connected to distribution line $440 \mathrm{~V}$. Table2 describes data of the transformer.

\begin{tabular}{|c|c|c|c|c|}
\hline No. & $\begin{array}{c}\text { Primary } \\
\text { volt } \\
(\mathrm{kV})\end{array}$ & $\begin{array}{c}\text { Secondary } \\
\text { volt(kV) }\end{array}$ & $\begin{array}{c}\text { Rating } \\
(\mathrm{kVA})\end{array}$ & Connection \\
\hline 1 & 11 & .44 & 450 & $\mathrm{D}_{11} \mathrm{Y}_{\mathrm{g}}$ \\
\hline
\end{tabular}

Table 2: Transformer data
In order to comply with simulation, the specified resistance and inductance of the windings are in per unit (p.u). The values are based on the transformer rated power $\mathrm{P}$ in VA, nominal frequency $\mathrm{f}$ in $\mathrm{Hz}$, and nominal voltage $\mathrm{V}$ in volt of the corresponding winding.

\subsection{THE FIX LOADS:}

The fixed loads are represented by resistive load. The nominal phase to phase voltage of the load is in volts RMS (Vrms) and three phase active power of the load is in watts $(\mathrm{W})$.

\subsection{Distributed GENERATION ${ }^{[6]}$ :}

This model consists of a unit synchronous machine (SM) equipped with distributed generation controller (DGC). The DGC is consisted of two important parts: hydraulic turbine governor and excitation. The SM model is a dynamic model of a three-phase round-rotor or salient-pole synchronous machine and operates in generator or motor modes. The operating mode is dictated by the sign of the mechanical power (positive for generator mode, negative for motor mode). The model SM provides a set of predetermined electrical and mechanical parameters for various synchronous machine ratings of power $(\mathrm{kVA})$, phase-to-phase voltage $(\mathrm{V})$, frequency $(\mathrm{Hz})$, and rated speed $(\mathrm{rpm})$ etc. Three DG units are connected at low voltage $(400 \mathrm{~V})$, with each capacity $150 \mathrm{kVA}, 50 \mathrm{~Hz}$ and maximum active power output is $120 \mathrm{~kW}$. 


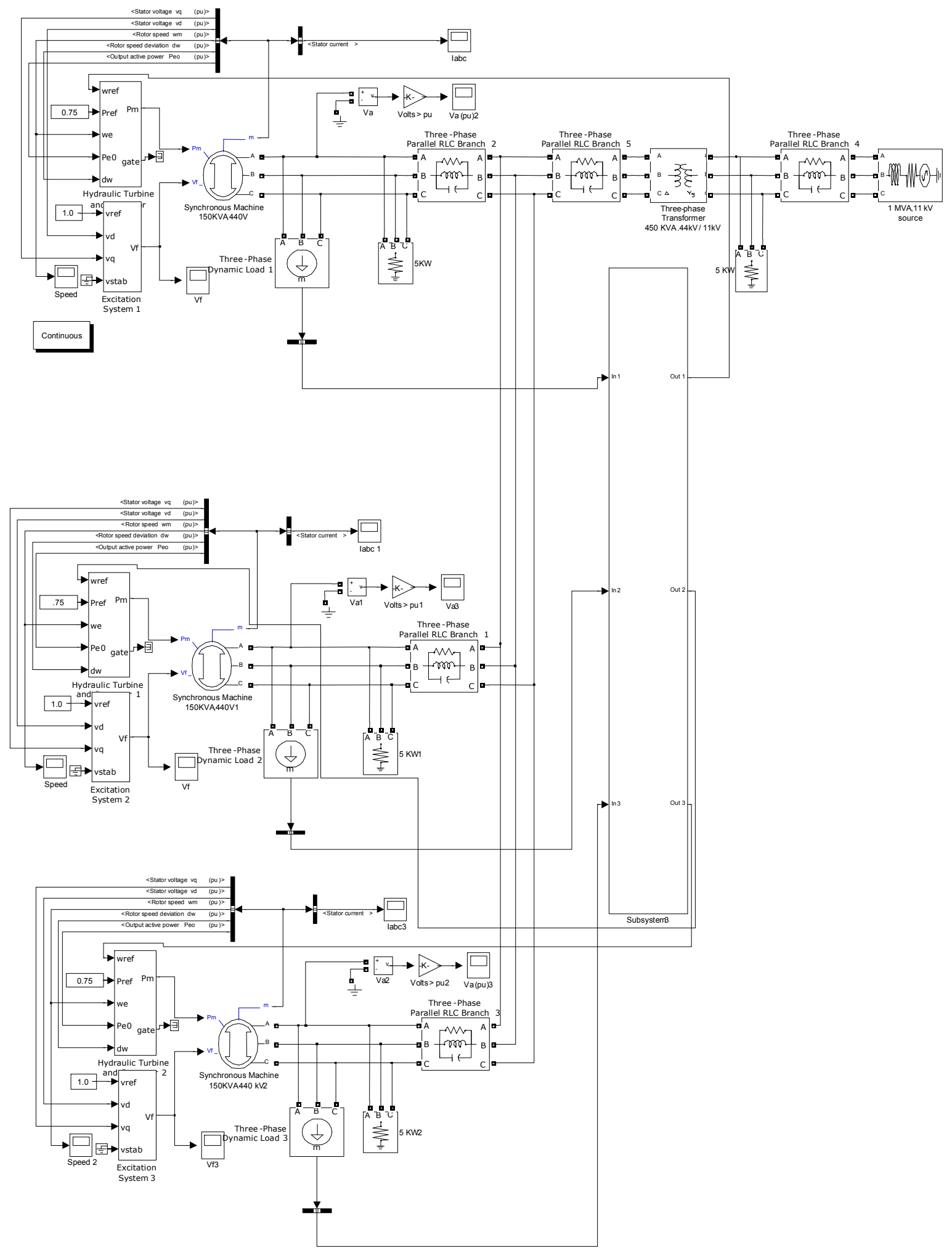

Figure 4: MATLAB design of centralized VPP for CUET 


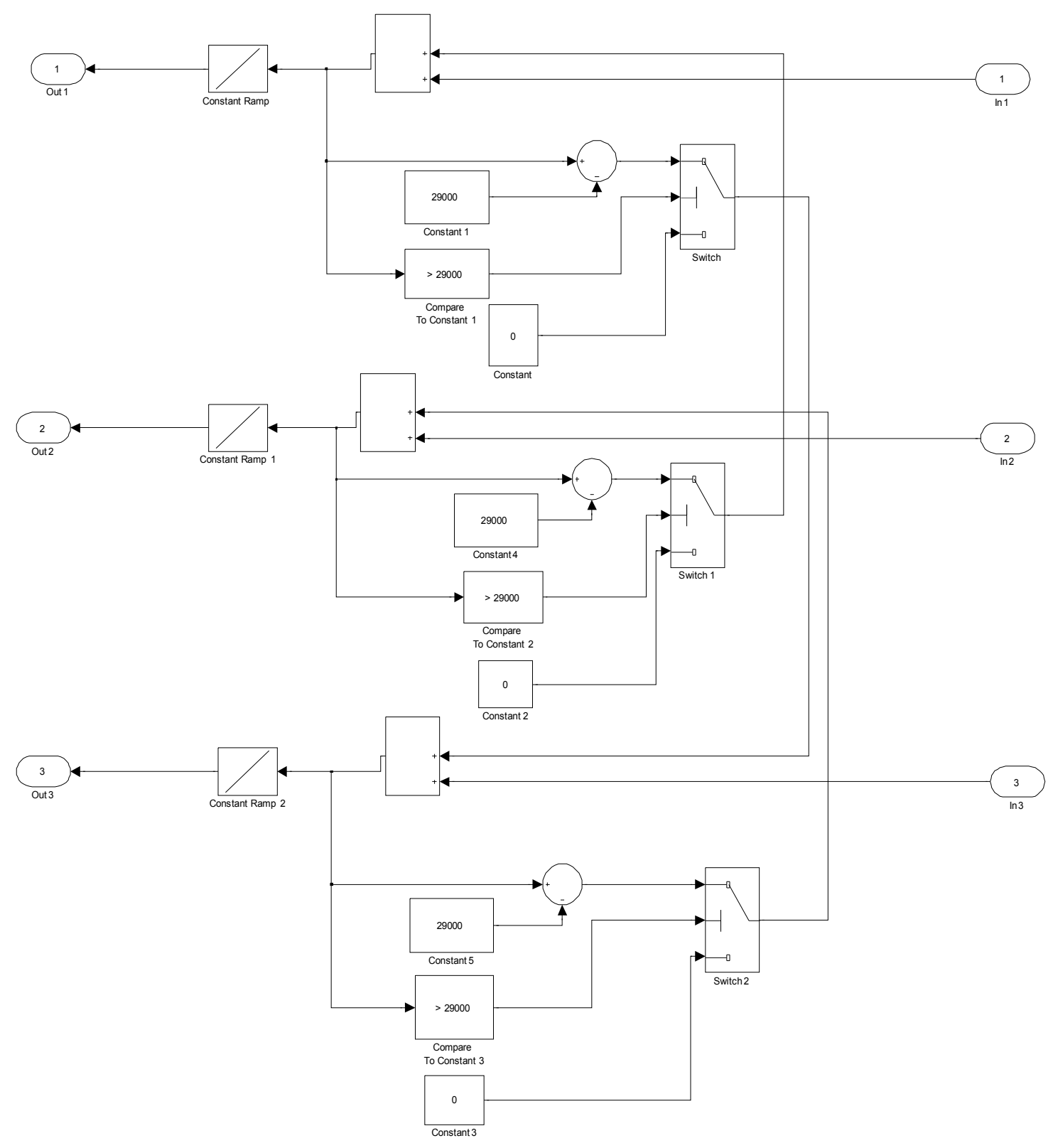

Figure 5: MATLAB design of subsystem.

\subsection{RESULT AND DISCUSSION \\ 6.1 CURVE OF STATOR CURRENT:}

The stator is the stationary part of a rotor system, found in an electric generator or electric motor. The rotating magnetic field induces an $\mathrm{AC}$ voltage in the stator windings. Often there are three sets of stator windings, physically offset so that the rotating magnetic field produces three phase currents, displaced by one-third of a period with respect to each other.

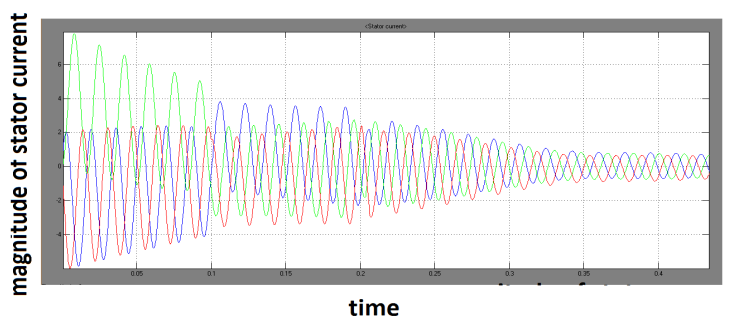

Figure 6a: Starting period of stator current.

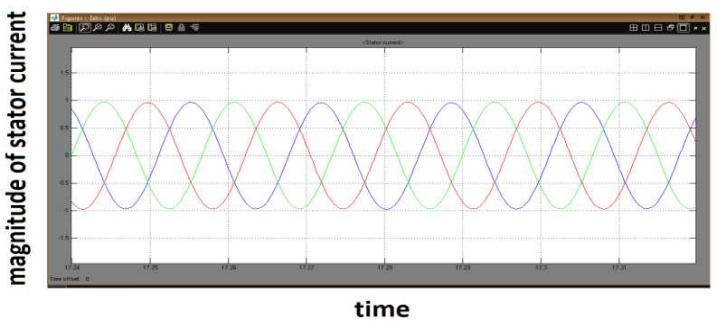

Figure 6b: Running period of stator current. 


\subsection{Curve OF Terminal Voltage:}

The initial terminal voltage and field voltage are set respectively to 1.0 and $1.291 \mathrm{pu}$. The terminal voltage $\mathrm{Va}$ is $1.0 \mathrm{pu}$ at the beginning of the simulation. It falls to about $0.4 \mathrm{pu}$ during the fault and returns to nominal quickly after the fault is cleared. This quick response in terminal voltage is due to the fact that the Excitation System output Vf can go as high as $11.5 \mathrm{pu}$, which it does during the fault and returns to nominal slowly after the fault is cleared.

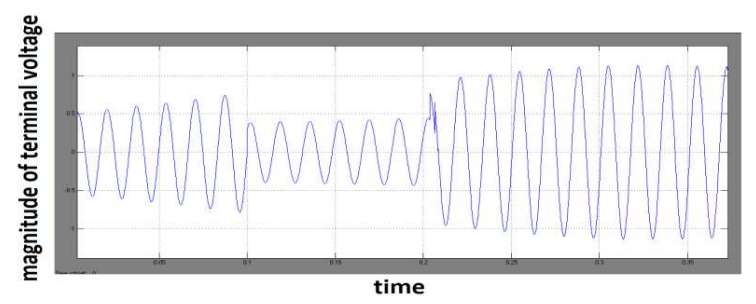

Figure 7a: Starting period of terminal voltage.

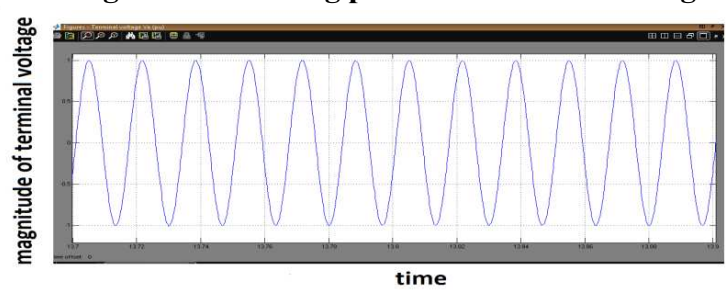

Figure 7b: Running period of terminal voltage.

\subsection{Curve of Field Voltage:}

Alternators generate electricity by the same principle as DC generators, namely, when the magnetic field around a conductor changes, a current is induced in the conductor. The rotor magnetic field may be produced by induction (in a "brushless" alternator), by permanent magnets (in very small machines), or by a rotor winding energized with direct current through slip rings and brushes. The rotor magnetic field may even be provided by stationary field winding, with moving poles in the rotor ${ }^{[7]}$.

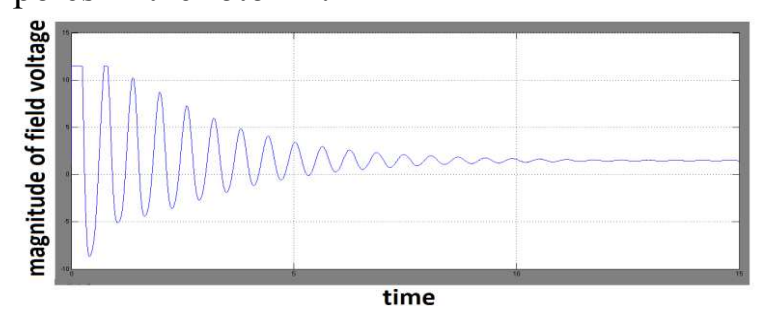

Figure 8: Curve of field voltage.

\subsection{CURVE OF Rotor SPEED:}

The output frequency of an alternator depends on the number of poles and the rotational speed. The speed corresponding to a particular frequency is called the synchronous speed for that frequency. From observation we can say that rotor speed varies with demanding load.

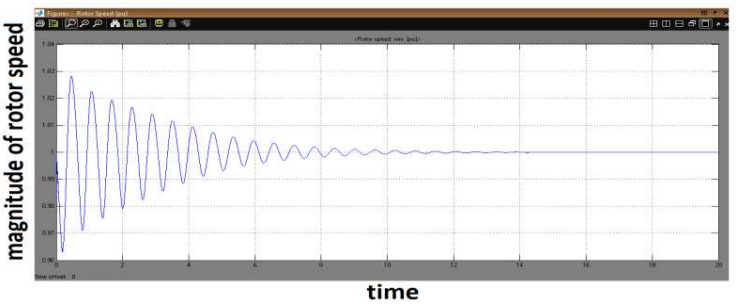

Figure 9: Curve of rotor speed.

The initial terminal voltage and field voltage are set respectively to 1.0 and $1.291 \mathrm{pu}$. The terminal voltage $\mathrm{Va}$ is (in figure $7 \mathrm{a}$ ) $1.0 \mathrm{pu}$ at the beginning of the simulation. It falls to about $0.4 \mathrm{pu}$ during the fault and returns to nominal (in figure 7b) quickly after the fault is cleared. This quick response in terminal voltage is due to the fact that the Excitation System output Vf can go as high as $11.5 \mathrm{pu}$ (in figure 8), which it does during the fault and returns to nominal slowly after the fault is cleared. The speed of the machine (in figure 9) increases to $1.01 \mathrm{pu}$ during the fault, then it oscillates around $1 \mathrm{pu}$ as the governor system regulates it. The speed takes much longer than the terminal voltage to stabilize, mainly because the rate of valve opening/closing in the governor system is limited to $0.1 \mathrm{pu} / \mathrm{s}$. The initial stator current (in figure 6a) is distorting before the stabilization is done and oscillate around $1 \mathrm{pu}$ after the stabilization is done (in figure $6 \mathrm{~b}$ ).

\subsection{Bus Voltage \& Angle Measurement:}
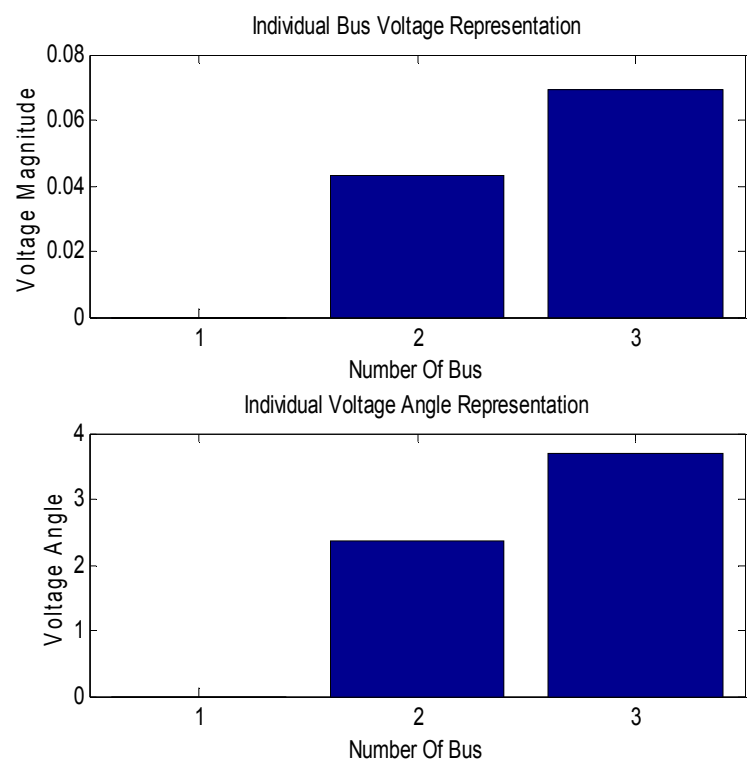

Figure 10: Individual bus voltage and angle representation.

In above figure bus 1 is slack bus, bus 2 is PV bus and bus 3 is PQ bus. As a result bus2 has lower voltage magnitude than bus3.Voltage angle is also smaller than bus 3 . 


\subsection{LIMITATIONS}

\section{LIMITATIONS OF THE SYSTEM: ${ }^{[8]}$}

1. Comparatively higher cost for Transmission capacity, physical grid \& energy infrastructure

2. Communication $\&$ information amount/speed may vary.

3. Fault may occur through communication channel.

4. Generic in hardwiring but partly application specific, e.g. Micro CHP, wind turbine, NG

\section{Limitations of the simulation:}

1. The speed of the simulation is unstable due to the memory acquisition problem caused by the MATLAB.

2. When we use Synchronous Machine blocks in discrete systems, we have to use a small parasitic resistive load, connected at the machine terminals, in order to avoid numerical oscillations. Large sample times require larger loads. The minimum resistive load is proportional to the sample time.

\subsection{Future Possibilities of The System}

The system can provide great flexibility to the power production and distribution. It can provide a greater advantage in the developing country like Bangladesh, Nepal, and Bhutan etc. ${ }^{[9]}$

For emergency power supply aggregation of generators are needed. On this perspective Aggregated Emergency power supply is foot-inthe-door.

Electricity exports are possible in facilities with very high thermal demands. This structure could enable investments in energy efficiency as part of the market for saved electricity.

By proper research any kind of renewable energy sources can be used to install it.

\subsection{Conclusion}

Bangladesh is now facing acute power crisis. To compete with the new millennium power crisis solution is immediately needed. As CUET is situated in rural area, load shedding occurs frequently. We have designed our vpp in such a way that it will not only reduce power crisis in CUET but also supply power to the main grid. Policymakers need to recognize the suffocating cost of allowing the power crisis to persist. Shortterm solutions may involve importing fuel to run smaller rental power units. But long-term, developing an effective public-private partnership, transparent procurement, constructing VPP and clear incentives for foreign investment along with greater integration with Burma, India and the Asian energy network should be an absolute priority for this government and the next .As VPP playing a good role in European \& American market, Our policy maker should take immediate steps about VPP.

\section{REFERENCES}

[1] Morten Decker: "Analysis and Design of an SOA for Virtual Power Plant", s011921 Kongens Lyngby 2008, page 4-5

[2] VPP concept, available at: http://www.newscientist.com/article/dn17290-virtualpower-plants-could-tame-coming-grid-chaos.html

[3] Sameer Shailesh Mundkur: "Design and implementation of a Digital Controller for High Power Converters",North CarolinaState University Raleigh, North Carolina 2008 page 13-15.

[4] SCADA, available at:

http://en.wikipedia.org/wiki/SCADA

[5] Ashfaq Hussain: "Electrical Power Systems" $4^{\text {th }}$ edition page: 177

[6] "Distributed Generation Architecture and Control", available at: http://www.rand.org/scitech/stpi/Evision/Supplement/s onderegger.pdf

[7] Stephen J. Chapman: "Electric machinery Fundamentals", $4^{\text {th }}$ edition, page: $308-314$.

[8] "Virtual power plant: basic requirements \& experience in practice", available at: www.ptius.com/pti/company/enewsletter/.../Virtual\%2 0Power\%20Plants.pdf

[9] Virtual power plant feasibility study: Federation of Canadian Municipalities, Final Report March 31st, 2006. page 28 